\title{
Investigation of laser shock peening effects on residual stress state and fatigue
} performance of titanium alloys

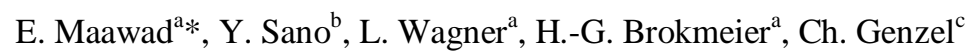 \\ ${ }^{a}$ Institute of Materials Science and Engineering, Clausthal University of Technology, Agricolastr. 6, D-38678 Clausthal- \\ Zellerfeld, Germany \\ ${ }^{\mathrm{b}}$ Toshiba Corporation, 8 Shinsugita-cho Isogo-ku Yokohama 235-8523, Japan \\ ${ }^{\mathrm{c}}$ Helmholtz-Zentrum Berlin (BESSY-II), Albert-Einstein-Str. 15, D- 12489 Berlin, Germany
}

\begin{abstract}
Laser shock peening can potentially enhance fatigue life of titanium components by inducing compressive residual stresses in surface layers much deeper than caused by traditional shot peening (SP). In the present study, the high cycle fatigue (HCF) performance of $\alpha$ Ti-alloy Ti2.5Cu, $(\alpha+\beta)$ Ti-alloy TIMETAL 54M and the metastable $\beta$ Ti-alloy TIMETAL LCB was investigated after laser shock peening without coating (LPwC). The fatigue results were interpreted by examining the changes of surface morphology, microhardness and residual stress generated in the surface layer. Furthermore, thermal stability of residual stresses in aged $\mathrm{Ti}-2.5 \mathrm{Cu}$, as an example, was evaluated after annealing LPwC-treated material at various elevated temperatures and exposure times by applying a Zener-Wert-Avrami-approach. The depth profiles of residual stresses were obtained by means of synchrotron X-ray diffraction or by incremental hole drilling method. Results revealed that the HCF performance of Ti-2.5Cu and TIMETAL LCB was markedly improved after LPwC, while it was deteriorated in TIMETAL 54M. Compared to LPwC, better $10^{7}$ fatigue strength of Ti-2.5Cu was obtained after ball-burnishing (BB). Moreover, LPwC-induced residual stresses are thermally more stable than shot peening-induced ones.
\end{abstract}

Keywords: Laser shock peening; fatigue; titanium alloys; residual stress; synchrotron X-ray diffraction.

\footnotetext{
* Corresponding author: Tel.: +49-05323-72-2760; fax: +49-05323-72-2766.

E-mail address: emad.k.s.maawad@tu-clausthal.de

Postal address: IWW, Agricolastr. 6, D-38678 Clausthal-Zellerfeld, Germany.
} 


\section{Introduction}

Titanium alloys are extensively used in the aerospace field such as jet-engine blades and gas turbine parts as well as emerging fields such as tools and sport products. This is attributed to higher specific strength and excellent corrosion resistance. These components are subjected to fatigue and fail due to flaws or cracks initiated on the surface. Therefore, surface layer properties of the components such as compressive layer play a major role in the fatigue performance. Compressive residual stresses on the surface retard the growth of surfaceinitiated cracks to which greatly prolongs the component life. Several processes are available for introducing beneficial compressive residual stresses in surface layers to enhance the fatigue performance. The most common of these methods is shot peening (SP), but laser shock peening (LSP) is receiving increased attention. LSP can produce deeper compressive residual stresses [1] with less cold work compared to that after SP. This allows less thermal relaxation of residual stresses after LSP when subjected to high temperatures [2]. On the fatigue performance of $\mathrm{Ti}-6 \mathrm{Al}-4 \mathrm{~V}$, crack initiation and early crack growth on aerofoil specimens due to foreign object damage (FOD) and subsequent fatigue crack growth were examined after applying LSP [3]. It was reported that LSP has improved the crack growth resistance post FOD. Delayed onset of crack initiation was observed in LSP specimens compared to those without LSP under similar loading conditions.

The major disadvantage of LSP is that it currently requires an elaborated laser system specially designed for production runs with high average power and large pulse energy up to, for example, $100 \mathrm{~J}$. On the other hand, laser shock peeing without coating ( $\mathrm{LPwC}$ ) utilizes a commercially available compact laser system with much smaller power and pulse energy of about $0.1 \mathrm{~J}[4,5]$. The effects of both processes, namely LSP and LPwC, are basically similar; however, the throughput of LSP is larger than that of LPwC due to the difference in the average power. Actually, the authors investigated residual stresses and work hardening of Ti2.5Cu after $\mathrm{LPwC}$ and compared with those after SP, ultrasonic shot peening (USP) and ball- 
burnishing (BB) [6]. Results revealed that LPwC produced the lowest cold work in the surface layer and rougher surface due to resolidified droplets and craters, while BB produced the highest maximum compressive residual stress. These results agree with the previous studies about the influence of LSP and BB on the residual stress state and work hardening of Ti-6Al4V [2]. Turski et al. [7] compared the efficacy of ultrasonic impact treatment (UIT), LSP and water jet cavitation peening (WJCP) at introducing residual stresses and modifying the near surface state compared to SP benchmark for AISI 304. It was concluded that WJCP and LSP introduced the lowest levels of surface roughening. Furthermore, the level of plastic work introduced by LSP and UIT is considerably less than that by SP, although the depth of plastic deformation extends to greater depths.

Recently, novel Ti-alloys have been available in the market such as $\alpha$ Ti-alloy Ti2.5Cu, $(\alpha+\beta)$ Ti-alloy TIMETAL 54M (in the following Ti-54M) and metastable $\beta$ Ti-alloy TIMETAL LCB (in the following LCB). Ti-2.5Cu or IMI 230 (ASM) combines the formability and weldability of unalloyed titanium with improved mechanical properties, particularly at elevated temperatures. This alloy is used in the annealed condition as sheets, forgings and extrusions for fabricating component such as bypass ducts of gas turbine engines [8]. Ti-54M was newly developed by TIMET, Henderson, NV (USA) with nominal composition Ti-5Al-4V-0.6Mo-0.4Fe (wt. \%) that can offer improved machinability and formability as compared to the well known Ti-6Al-4V [9]. This alloy is being evaluated for both aerospace and non-aerospace applications. LCB was developed targeting automotive suspension spring applications. The nominal chemical composition of this alloy is Ti-1.5Al6.8Mo-4.5Fe (wt. \%). The formulation cost of this alloy is lowered by adding Mo and $\mathrm{Fe}$ in the form of a ferro-molybdenum master alloy $[10,11]$.

In the present study, fatigue performance of Ti-2.5Cu, Ti-54M and LCB Ti-alloys has been investigated by examining the surface morphology, microhardness and residual stresses induced in the surface layers after LPwC. In addition, residual stresses generated in the $\alpha$ - 
phase or $\beta$-phase in the surface layers were independently evaluated by energy dispersive $\mathrm{X}$ ray diffraction using synchrotron radiation. Thermal stability of residual stresses in $\mathrm{Ti}-2.5 \mathrm{Cu}$ was also examined.

\section{Experimental procedures}

\subsection{Material and phase analysis}

Ti-2.5Cu was received as a $10 \mathrm{~mm}$ thick rolled plate. Twelve blanks were cut from this plate with dimension of $20 \times 20 \times 5 \mathrm{~mm}^{3}$ for residual stress measurements. Solution heat treatment at $805{ }^{\circ} \mathrm{C}$ for 1 hour was applied to the blanks followed by water-quenching and then double aging by annealing the material at $400{ }^{\circ} \mathrm{C}$ for 8 hours as well as annealing at $475^{\circ} \mathrm{C}$ for 8 hours.

Ti-54M was received as a square $(38 \times 38 \mathrm{~mm})$ bar stock in as-milled condition. A cut bar with a length of $50 \mathrm{~mm}$ was $\beta$-annealed at $1010{ }^{\circ} \mathrm{C}$ for $30 \mathrm{~min}$ followed by waterquenching. This bar was unidirectionally rolled at $800{ }^{\circ} \mathrm{C}$ with a total deformation degree of $\varphi$ $=1.4$. From the rolled plates, twelve blanks were cut with dimension of $20 \times 20 \times 5 \mathrm{~mm}^{3}$ and were heat treated to obtain a fully equiaxed microstructure by annealing at $800{ }^{\circ} \mathrm{C}$ for 1 hour followed by water-quenching. All blanks were given a final heat treatment at $500{ }^{\circ} \mathrm{C}$ for 24 hours to age-harden the $\alpha$-phase by $\mathrm{Ti}_{3} \mathrm{Al}$ precipitates and the $\beta$-phase by fine secondary $\alpha$ precipitates.

LCB was received as a swaged rod of $14.3 \mathrm{~mm}$ in diameter. The rod was unidirectionally rolled at $760^{\circ} \mathrm{C}$ to a thickness of $5 \mathrm{~mm}$ corresponding to a maximum deformation degree of about $\varphi=1$. Twelve blanks $\left(20 \times 20 \times 5 \mathrm{~mm}^{3}\right)$ were cut from the plate and recrystallization annealed at $760^{\circ} \mathrm{C}$ for 1 hour followed by water quenching. The blanks were final heat treated at $540^{\circ} \mathrm{C}$ for 8 hours followed by air cooling.

The phase analysis of Ti-54M and LCB was performed using synchrotron radiation at DESY in Hamburg (beamline W2) with a fitted wavelength of $0.1262 \AA(98.25 \mathrm{keV})$ using 
the diffraction pattern of $\mathrm{Zn}$ powder. The distance between the sample and the area detector was $1166 \mathrm{~mm}$. The results were obtained after fitting by MAUD (Material Analysis $\underline{\text { Using }}$ Diffraction) software [12]. It is a general diffraction/reflectivity analysis program mainly based on the Rietveld method to refine the diffraction spectra as explained in details elsewhere [13].

\subsection{Tensile and fatigue testing}

Three threaded cylindrical tensile specimens of $\mathrm{Ti}-2.5 \mathrm{Cu}$ and $\mathrm{Ti}-54 \mathrm{M}$ were machined having a gage length of $20 \mathrm{~mm}$ and a diameter of $4 \mathrm{~mm}$. Tensile test was also conducted on LCB flat specimen having a gage length of $30 \mathrm{~mm}$, a width of $8 \mathrm{~mm}$ and a thickness of $3 \mathrm{~mm}$. All tests were carried out at ambient temperature with an initial strain rate of $10^{-3} \mathrm{~s}^{-1}$. Tensile properties of the alloys are listed in Table 1.

High cycle fatigue (HCF) tests were performed on eight hour-glass shaped specimens for each material and condition in rotating beam loading $(\mathrm{R}=-1)$ with a minimum diameter of $3 \mathrm{~mm}$ and a frequency of $50 \mathrm{~Hz}$ in air.

\subsection{Laser shock peening without coating (LPwC)}

The scheme of the experimental setup is illustrated in Fig. 1. The fundamental wave of a Q-switched Nd:YAG laser $(\lambda=1.06 \mu \mathrm{m})$ is frequency-doubled to a water-penetrable wave $(\lambda=532 \mathrm{~nm})$ by a second harmonic generator with a nonlinear optical crystal. The laser beam is focused through a plano-convex lens and irradiated on a test specimen without coating in a water jacket through a fused quartz window. The sample is fixed on a holder and driven to the $\mathrm{x}$ - and $\mathrm{y}$-directions during the irradiation of the laser pulses. The ablation products generated on the sample were removed by water flow to minimize the scattering loss of the in-coming laser pulse. The major experimental parameters on $\mathrm{LPwC}$ are irradiating laser pulse energy $\left(\mathrm{E}_{\mathrm{p}}\right)$, laser spot diameter (D) and laser pulse density $\left(\mathrm{N}_{\mathrm{p}}\right) . \mathrm{E}_{\mathrm{p}}$ is tuned with a variable 
attenuator, and $\mathrm{D}$ is adjusted by varying the distance between the lens and the specimen. In case of flat specimens, $\mathrm{N}_{\mathrm{p}}$ is simply determined with the driving speed of the specimen in the $\mathrm{x}$-direction and the step size in the y-direction in Fig. 2, which shows the typical procedure of laser irradiation on plate specimens. The laser irradiation conditions are summarized in Table 2. The coverage $\left(C_{v}\right)$ is calculated by $C_{v}=A_{p} \cdot N_{p}$, where $A_{p}$ is the beam spot area. The peak power density $(G)$ is defined as $G=E_{p} /\left(A_{p} \cdot t\right)$, where $t$ is the duration of the laser pulse in full width at half maximum (FWHM) and is $8 \mathrm{~ns}$ in the present experiments.

\subsection{Microhardness}

Microhardness was determined by means of a Struers Duramin tester using a square base pyramid shaped indenter for testing in a Vickers tester, a nominal force of $100 \mathrm{gf}$ (HV0.1) and a loading time of 10 seconds. The hardness testers in the Duramin series conform to the standard (DIN EN ISO 6507). The average of three measurements was taken at each depth on the cross-section of the specimens to construct the hardness-depth profiles.

\subsection{Surface roughness}

The surface roughness was determined by means of an electronic contact (stylus) profilometer instrument (Perpethometer). The average absolute value of the five highest peaks and the five lowest valleys over the evaluation length $\left(R_{z}\right)$ was reported (DIN 4768). The average of three roughness measurements was taken. The parameter $\left(\mathrm{R}_{\mathrm{z}}\right)$ was used rather than the average roughness $\left(\mathrm{R}_{\mathrm{a}}\right)$ comparing all the peaks and valleys to the mean line, because quite different surfaces could have the same $\mathrm{R}_{\mathrm{a}}[14]$.

\subsection{Residual stresses}

Residual stress measurements were performed by hard X-ray diffraction using synchrotron radiation at BESSY-II in Berlin. The characteristic of the used beamline EDDI 
offers a white X-ray beam with an energy range of 10-80 keV. The primary beam crosssection was set to $0.5 \times 0.5 \mathrm{~mm}^{2}$. The angular divergence in the diffracted beam was restricted to $\Delta \theta \leq 0.005^{\circ}$ by a double slit system with apertures of $0.03 \times 5 \mathrm{~mm}^{2}$. The scattering angle was chosen to $8^{\circ}$ considering the energy of X-ray. Energy-dispersive X-ray diffraction (EDXRD) gives complete diffraction spectra for a fixed detector position. Any Bragg reflection was obtained by a different X-ray energy (wavelength), i.e. the signal of any reflection belongs to a different depth in the specimen as schematically shown in Fig. 3. Due to the limited usable energy range provided by the $7 \mathrm{~T}$ multipole wiggler which extends from about $10 \mathrm{keV}$ to $80 \mathrm{keV}$, the maximum information depth for titanium accessible in reflection mode experiments is about $100 \mu \mathrm{m}$. In order to get a stress distribution in deeper region, two or three specimens were prepared for each condition. For the one or two of them, layer removal in a step of 100-150 $\mu \mathrm{m}$ was applied by electropolishing. The correction on the measured residual stress was made for the electropolished specimens using the equation described elsewhere [15]. Residual stresses were evaluated by means of the $\sin ^{2} \psi$ method, where $\psi$ is the tilting angle, in steps of $\Delta \psi=4^{\circ}$ up to $80^{\circ}$. A modified multi-wavelength approach [16] for any energy line $\mathrm{E}_{(\mathrm{hk} .1)}$ gives an average penetration depth $\tau_{(\mathrm{hk} . \mathrm{l})}(\mathrm{Eq} .1)$ :

$\tau_{(\mathrm{hk} . \mathrm{l})}=\left(\tau_{(\mathrm{hk} . \mathrm{l}) \min }+\tau_{(\mathrm{hk} . \mathrm{l}) \max }\right) / 2$

where $\tau_{(\mathrm{hk} . \mathrm{l}) \min }$ and $\tau_{(\mathrm{hk} . \mathrm{l})} \max$ are the minimum and the maximum penetration depths corresponding to the maximum $\left(\psi_{\min }\right)$ and minimum $\left(\psi_{\max }\right)$ tilting angles, respectively. The $\mathrm{X}$ ray diffraction elastic constants of $\alpha$ - and $\beta$-phases were calculated by the Kröner-Model [17].

Residual stresses at the surface were determined by using laboratory X-ray diffraction (D-5000 at TU Clausthal) using $\mathrm{Cu}-\mathrm{K} \alpha$-radiation with a wavelength of $1.54 \AA$. The $\{21.3\}$ Bragg peak was used with diffraction elastic constants of $\mathrm{S}_{1}=-2.88 \times 10^{-6} \mathrm{MPa}^{-1}$ and $1 / 2 \mathrm{~S}_{2}=$ $11.74 \times 10^{-6} \mathrm{MPa}^{-1}$. The $\sin ^{2} \psi$ method was also used to evaluate the surface residual stresses with tilting angles range of $-45^{\circ}$ to $+45^{\circ}$ in steps of $\Delta \sin ^{2} \psi=0.125$. 
Thermal relaxation of residual stress in $\mathrm{Ti}-2.5 \mathrm{Cu}$ was studied by carrying out isothermal annealing at different temperatures (T) $\left(300,400\right.$ and $\left.475{ }^{\circ} \mathrm{C}\right)$ for different times (t) $(3,9$, and $18 \mathrm{~h})$ by means of the incremental hole drilling method according to ASTM E 837-01. This method involves attaching strain gage rosette to the surface, drilling a hole in the vicinity of the gages and measuring the relieved strains using an oscillating drill with diameter of $1.9 \mathrm{~mm}$ driven by an air-turbine with a rotational speed of 200,000 rpm.

\section{Results and discussions}

\subsection{Microstructure and phase analysis}

The microstructure and phase analysis of $\mathrm{Ti}-2.5 \mathrm{Cu}$, Ti-54M and LCB were studied before performing LPwC. Obviously, the microstructure of Ti-2.5Cu consists of $\alpha$ grains and stringers of the eutectoid component $\alpha+\mathrm{Ti}_{2} \mathrm{Cu}$ (dark phase) as shown in Fig. 4a. Indeed, aging at $400{ }^{\circ} \mathrm{C}$ in the preparation of the specimens leads to a homogeneous nucleation of the precipitations $\left(\mathrm{Ti}_{2} \mathrm{Cu}\right)$ and dislocations. The other aging at $475{ }^{\circ} \mathrm{C}$ forms homogeneously the precipitation resulting in an increase of the tensile strength.

The microstructure of Ti-54M is fully equiaxed (EQ) with the equilibrium volume fraction of $\beta$-phase (dark phase) located at the triple-points of the $\alpha$-grain boundaries. The equiaxed $\alpha$-grain sizes in Ti-54M amount to about $3 \mu \mathrm{m}$ (Fig. 4b).

The microstructure of LCB is illustrated in Fig. 4c. The thermo-mechanical treatment resulted in equiaxed primary $\alpha$-phase (light phase) with a size of $2 \mu \mathrm{m}$ located at the grain boundary triple points of the $\beta$-grains (dark phase). During final heat treatment, fine secondary $\alpha$-particles were precipitated out from the $\beta$-matrix leading to marked agehardening.

It was essential to determine the volume fractions of $\alpha$ - and $\beta$-phases in Ti-54M and LCB, because they play a key role to correlate the microstructure with the material behaviors. It is known that diffraction peak intensities depend upon volume fractions of different phases 
and grain orientations (crystallographic texture). The volume fractions of $\alpha$ - and $\beta$-phases in Ti-54M and LCB were evaluated by using synchrotron radiation. The Debye-Scherrer rings of Ti-54M (Fig. 5a) and LCB (Fig. 5c) clearly show the presence of crystallographic texture. In the present work, the specimens were rotated during the measurement to obtain the intensity distribution of each crystalline plane (pole figure). These measured intensities were integrated to overcome the texture influence on the volume fraction calculations. Therefore, sum diffraction spectra of Ti-54M (Fig. 5b) and LCB (Fig. 5d) using the pole figure data were refined by using MAUD software with taking into account the texture correction. Using this procedure, the volume fractions, weight fractions and lattice constants of the $\alpha$ - and $\beta$-phases were calculated and listed in Table 3. On the other hand, the phase analysis result of Ti-54M reported in [18] was obtained by performing a single shot of synchrotron beam without specimen rotation, i.e. the contribution of grain orientations were partially considered when calculating the volume fractions. This can lead to relatively less reliable results.

\subsection{Surface morphology}

The surface roughness $\left(\mathrm{R}_{\mathrm{z}}\right)$ of Ti-2.5Cu, Ti-54M and LCB specimens after LPwC is shown in Fig. 6. Surface vaporization was still induced by $\mathrm{LPwC}$ with much smaller power and short pulse duration compared to LSP. This led to re-solidified droplets increasing the surface roughness. This is also the reason why no significant difference among the roughness values $\left(\mathrm{R}_{\mathrm{z}}\right)$ in the different Ti-alloys was observed in spite of different tensile properties. This is in contrast to SP, BB or USP which generally increases the roughness of electropolished surface (EP) of Ti-2.5Cu by smaller magnitude compared to LPwC (see Fig.7) [6]. This rougher surface associated with LPwC may lead to more significant deterioration in resistance to fatigue-crack initiation and corresponding fatigue life than that with the other treatments. Nevertheless, this feature of LPwC could achieve more favourable interaction between the implant and biological tissues compared to, for example, BB or USP. 
Scanning electron microscope (SEM) was used to examine the surface morphology in Ti-2.5Cu (Fig. 8a), Ti-54M (Fig. 8b) and LCB (Fig. 8c). Results revealed that microcracks were developed at the surface during LPwC. The top surface of the specimens slightly melts or evaporates (less than $1 \mu \mathrm{m}$ from the surface) through ablative interaction between the intense laser pulses and the surface. Therefore, the ablative product is ejected away from the surface; however, some part of the product remains on the surface or a part of the product resolidifies through water cooling and piles on the surface. The re-solidified material may be oxide and brittle. During cooling down, it shrinks and some microcracks develop to relax the stress due to shrinkage. As seen in Fig. $8 \mathrm{~b}, \mathrm{LPwC}$ produced not only microcracks but also relatively more cavities (indicated by arrows) in Ti-54M surface compared to those in Ti2.5Cu and LCB surfaces. This could be explained by large coefficient of thermal expansion (CTE) of $\mathrm{Al}$ [19], whose composition is higher in Ti-54M (wt. 5\%) than in LCB (wt. 1.5\%).

\subsection{Microhardness-depth profiles}

The microhardnes-depth profiles in Ti-2.5Cu, Ti-54M and LCB specimens after LPwC are illustrated in Fig. 9. It is clearly shown that the maximum microhardnes was produced in the surface layer which gradually decreased in the bulk region. The variation of the hardness value and the plastic deformation depth in each alloy is explained by different tensile properties (Table 1). The highest bulk hardness and the smallest deformation depth in LCB (455 HV0.1) are attributed to relatively higher yield and tensile strengths compared to those in Ti-2.5Cu and Ti-54M. By normalizing the hardness values at the surface to the bulk values, it was found that the increases of microhardness by $\mathrm{LPwC}$ in the investigated alloys are similar.

In order to interpret the fatigue behavior of $\mathrm{Ti}-2.5 \mathrm{Cu}$ after $\mathrm{LPwC}$ compared with various surface treatments as explained later, the microhardness results reported in [6] are briefly introduced. Microhardness produced in Ti-2.5Cu by LPwC, SP with Almen intensity of $0.20 \mathrm{mmA}$ using S330 shots, USP with the same Almen intensity using 100Cr6 bearing 
steel balls and BB with pressure of 300 bar using HG6 ball was compared (Fig. 10). Results revealed that repeated dimpling at the surface by SP to achieve uniform surface coverage resulted in higher cold worked layer or dislocation density [20] than LPwC. This is a result of the stress created by shock wave propagation rather than cold work as in SP. This lower magnitude of microhardness after LPwC supports the hardness results of LSP on hypoeutectoide steel [1]. On the other hand, USP produced relatively greater microhardness than LPwC and lower than SP and BB. This is explained by a large size of the balls used in USP process those can fully cover larger area with shorter time compared to that in SP process. This feature of $\mathrm{LPwC}$ leads to a thermal stability of residual stress close to the surface as explained later.

\subsection{Residual Stress}

\subsubsection{Residual Stress-depth Profile}

The effect of $\mathrm{LPwC}$ on residual stress in $\mathrm{Ti}-2.5 \mathrm{Cu}$ was examined in the scanning direction of the laser beam (in the following x-direction) and perpendicular to the scanning direction (in the following y-direction). Because LPwC was performed sequentially on both specimen sides of $20 \times 20 \mathrm{~mm}^{2}$ areas, residual stress was determined on the first side treated by LPwC (in the following side-1) and on the second side (in the following side-2). The residual stress-depth profiles in different directions and sides are illustrated in Fig. 11. The treatment being different in the $\mathrm{x}$ - and $\mathrm{y}$-directions resulted in that the magnitude of the residual stress in $\mathrm{y}$-direction $\left(\sigma_{\mathrm{y}}\right)$ after $\mathrm{LPwC}$ is larger than that in $\mathrm{x}$-direction $\left(\sigma_{\mathrm{x}}\right)$ in the surface region which is still an opened question. Therefore, further investigation is needed to study the influence of some processing and/or material factors on the residual stress components. Furthermore, it was observed a slight difference between residual stress components on the side- 1 and side- 2 . The residual stress generated on the side- 1 is more 
compressive than that on the side-2. This might be a result of the influence of specimen bending after LPwC on the side-1.

In the present work, the residual stress component $\sigma_{\mathrm{y}}$ induced in the $\alpha$-phase on the side-1 of Ti-2.5Cu, Ti-54M and LCB is compared as shown in Fig. 12. The difference of the residual stresses among these alloys is explained by the difference in the yield strength. Ti$54 \mathrm{M}$ has larger yield strength than $\mathrm{Ti}-2.5 \mathrm{Cu}$. Therefore, the potential maxima of the induced residual stress by plastic deformation are larger in Ti-54M. Furthermore, lower hardness and higher ductility in $\mathrm{Ti}-2.5 \mathrm{Cu}$ resulted in relatively deeper compressive layer compared to Ti$54 \mathrm{M}$ and LCB.

Although the yield strength of LCB is higher than that of Ti-2.5Cu or Ti-54M, the residual stress is lower. This can be explained by smaller volume fraction of the $\alpha$-phase (about 15\%) in LCB compared to that in Ti-54M (about 85\%) as listed in Table 3. Therefore, the residual stress induced in the $\beta$-phase of LCB was also determined (Fig. 13) and compared to that in the $\alpha$-phase, while it was difficult to evaluate this stress in the $\beta$-phase of Ti-54M due to a small volume fraction and inadequate diffraction intensities to fit the $\beta$-reflections. Obviously, compressive residual stresses in the $\beta$-phase are markedly higher than in the $\alpha$ phase. This can be explained by the presence of fine secondary $\alpha$-particles in the $\beta$-matrix which are precipitated out during the final aging treatment. These hcp precipitates being incoherent to the bcc $\beta$-matrix not only lead to a homogenization of the slip distribution during plastic deformation but also stabilize the work hardening states of the $\beta$ microstructure.

Laser shock peening without any ablative layer or LPwC could lead to tensile stresses at the surface probably due to local melting. Therefore, the residual stress at the surface was determined by using laboratory X-ray diffraction with a relatively smaller penetration depth compared to synchrotron diffraction. The results revealed that the surface residual stresses are also compressive, as listed in Table 4, due to a large number of laser hits (16 hits) (see Table 
2). The difference among these surface residual stresses can be explained by different local yield stresses at the surface.

Residual stresses produced in $\mathrm{Ti}-2.5 \mathrm{Cu}$ by $\mathrm{LPwC} \mathrm{SP}, \mathrm{BB}$ and USP were compared (Fig. 14). It was observed that SP and USP produced nearly the same residual stress up to 250 $\mu \mathrm{m}$ in depth, if the error bars are taken into account. The same Almen intensity used in SP and USP could be the reason why the residual stress distributions are nearly the same. However, LPwC produced much deeper compressive layer compared to SP and USP. Obviously, BB produced the greatest amount and penetration depth of maximum residual stress in the surface layer compared to the others.

\subsubsection{Thermal Stability of Residual Stress}

The thermal stability of maximum residual stress in $\mathrm{Ti}-2.5 \mathrm{Cu}$, as an example, after LPwC has been investigated and compared with SP which markedly produced higher plastic deformation in the surface layer than LPwC. It should be pointed out that $\mathrm{Ti}-2.5 \mathrm{Cu}$ has microstructure stability after aging. Therefore, it is expected no additional residual stresses induced during annealing.

Time and temperature influences on the residual stress relaxation during annealing are controlled by a thermally activated process and can be described by a Zener-Wert-Avrami function [21] as:

$$
\frac{\sigma^{\mathrm{RS}}(\mathrm{t}, \mathrm{T})}{\sigma^{\mathrm{RS}}(\mathrm{t}=0)}=\exp \left[-\left(\mathrm{C} \cdot \mathrm{t} \exp \left(\frac{\Delta \mathrm{H}}{\mathrm{kT}}\right)\right)^{\mathrm{m}}\right]
$$

where $\sigma^{\mathrm{RS}}(\mathrm{t}, \mathrm{T})$ is the magnitude of the residual stress after isothermal annealing for time $\mathrm{t}$ at the absolute temperature $\mathrm{T}, \sigma^{\mathrm{RS}}(\mathrm{t}=0)$ is the initial residual stress at room temperature, $\Delta \mathrm{H}$ is the activation enthalpy of the rate controlling process, $\mathrm{m}$ is an exponent, $\mathrm{C}$ is a velocity constant and $\mathrm{k}$ is the Boltzmann constant $\left(8.617 \times 10^{-5} \mathrm{eV} \cdot \mathrm{K}^{-1}\right)$. Based on Eq. 2, in order to 
obtain the values of $\Delta H, m$ and $C$, the diagram of $\lg \left[\ln \left(\sigma^{R S}(t=0) / \sigma^{R S}(t, T)\right)\right]$ as the function of $\lg (\mathrm{t})$ was presented for each surface treatment as shown in Fig. 15. The calculated parameters are listed in Table 5. Obviously, the rate of maximum residual stress relaxation was faster (larger slop "m") in the shot peened surface layer (Fig. 15a) than that in the surface layer after LPwC (Fig. 15b). The higher magnitude and rate of relaxation of the compressive layer developed by SP were attributed to greater microhardness or dislocation density produced at the depth of maximum residual stress (about $75 \mu \mathrm{m}$ ) compared to those by LPwC (see Fig. 10). This higher thermal stability of the residual stress after LPwC supports the previous thermal stability results of Ti-6Al-4V and Inconel 718 after LSP [20]. This feature of LSP or LPwC may lead to relatively stable fatigue properties at elevated temperature. However, the amount of dislocation density and microstructure stability in the surface layer play more significant role for fatigue performance at elevated temperature than residual stress stability as reported in [2,22-23]. The results in the previous researches revealed that, at elevated test temperatures, the fatigue lifetime of the BB condition is higher than that of the LSP condition due to more stable near-surface microstructures, e.g. nanocrystalline layers and higher dislocation densities.

\subsection{Fatigue Performance}

The S-N curves in rotating beam loading in air of $\mathrm{Ti}-2.5 \mathrm{Cu}$ are shown in Fig. 16a, comparing LPwC condition with the electropolished references (EP), SP and BB. The high cycle fatigue (HCF) performance of EP Ti-2.5Cu was improved by LPwC. The $10^{7}$ cycles fatigue strength increased from $425 \mathrm{MPa}(\mathrm{EP})$ to $575 \mathrm{MPa}$ after $\mathrm{LPwC}$, while it increased to $525 \mathrm{MPa}$ and $625 \mathrm{MPa}$ after $\mathrm{SP}$ and $\mathrm{BB}$, respectively. The greater amount and penetration depths of compressive residual stresses after BB as opposed to LPwC and SP are thought to be the reason for the more pronounced improvement of the HCF strength after BB (Fig. 14). Furthermore, this is related to the greater depth of the fatigue crack nucleation site of about 
$500 \mu \mathrm{m}$ compared to $200 \mu \mathrm{m}$ (SP and LPwC) underneath the surface under quasi-vacuum condition (Fig. 17a). Therefore, detrimental effects of the surface roughness on the fatigue performance can be reduced after applying surface treatments. Nevertheless, it was observed that the HCF strength of Ti-54M after LPwC decreased from $650 \mathrm{MPa}(\mathrm{EP})$ to $550 \mathrm{MPa}$ (LPwC) as illustrated in Fig. 16b. This could be explained by existence of more cavities at the surface (Fig. 8b) which could accelerate the crack nucleation at the surface beside subsurface crack nucleation (Fig. 17b). On the contrary, K. Zay et al. [18] reported that the HCF performance of Ti-54M was slightly improved after SP and markedly improved after BB due to a normal mean stress sensitivity of that alloy. It should be pointed out that the shot media used in the present study and in Ref. [18] were S330 and SCWW14, respectively. Further investigations should be carried out on Ti-54M by either removing a shallow layer (about 30$50 \mu \mathrm{m})$ from the surface after LPwC by electropolishing as reported elsewhere [24] for increasing the fatigue life of $\mathrm{Ti}-6 \mathrm{Al}-4 \mathrm{~V}$ or by optimizing $\mathrm{LPwC}$ parameters to obtain reasonable surface quality without coating and enhancement of fatigue performance.

The S-N curves in rotating beam loading $(\mathrm{R}=-1)$ in air of LCB after LPwC and EP are shown in Figure 16c. Obviously, the HCF fatigue strength markedly increased from 650 $\mathrm{MPa}(\mathrm{EP})$ to $800 \mathrm{MPa}$ after LPwC. This is also explained by the compressive residual stress induced in the surface layer and subsurface crack nucleation under quasi-vacuum condition (Fig. 17c). Moreover, the higher HCF strength of LCB (EP) compared to that of Ti-2.5Cu (EP) is attributed to higher yield and tensile strengths of LCB, while the HCF strengths of LCB (EP) and Ti-54M (EP) are the same.

\section{Conclusion}

The presented results indicate that the high cycle fatigue (HCF) performance of Ti2.5Cu was more improved by applying laser shock peening without coating ( $\mathrm{LPwC})$ than that by applying conventional shot peening (SP). This is due to the greater amount and depth of 
compressive residual stresses in the surface layer after LPwC. Furthermore, the compressive residual stresses are thermally more stable in LPwC surface layer than those in SP surface layer. On the other hand, ball-burnishing process (BB) resulted in better HCF performance than $\mathrm{LPwC}$. The same beneficial influence of $\mathrm{LPwC}$ on Ti-2.5Cu was also observed for LCB. On the contrary, LPwC deteriorated the HCF performance of Ti-54M. It was argued that the reason could be the existence of more cavities at the surface which accelerates the crack initiation.

\section{Acknowledgment}

The authors are indebted to the German Research Foundation (DFG) for financial support through BR961/5-2 and WA 692/32-2. We acknowledge the Helmholtz-Zentrum Berlin Electron storage ring BESSY II for provision of synchrotron radiation at beamline EDDI and would like to thank Dr. M. Klaus and Mr. M. Jiang for assistance. The research leading to these results has received funding from the European Community's Seventh Framework Program (FP7/2007-2013) under grant agreement No. 226716. Also, we would like to thank Mr. H. Polanetzki and Mr. J. Ehrl of MTU Aero Engines GmbH, Munich, for assistance to perform the ultrasonic shot peening process.

\section{References}

[1] J.-E. Masse and G. Barreau, Surf. Coat. Technol. 70 (1995) 231-234.

[2] R.K. Nalla, I. Altenberger, U. Noster, G.Y. Liu, B. Scholtes, R.O. Ritchie, Mater. Sci. Eng. A355 (2003) 216-230.

[3] S. Spanrad, J. Tong, Mater. Sci. Eng. A 528 (2011) 2128-2136.

[4] Y. Sano, N. Mukai, K. Okazaki and M. Obata, Nucl. Instrum. \& Methods Phys. Res. B, 121(1997) 432-436.

[5] Y. Sano, M. Obata, T. Kubo, N. Mukai, M. Yoda, K. Masaki and Y. Ochi: Mater. Sci. 
Eng. A 417 (2006) 334-340.

[6] E. Maawad, H.-G. Brokmeier, L. Wagner, Y. Sano and Ch. Genzel, Surf. Coat. Technol. 205 (2011) 3644-3650.

[7] M. Turski, S. Clitheroe, A. D. Evans, C. Rodopoulos, D. J. Hughes, P. J. Withers, Appl Phys A 99 (2010)

[8] ASM Handbook, Materials Properties, Titanium Alloys, Ohio, 1994, p 415.

[9] V. Venkatesh, Y. Kosaka, J. Fanning, S. Nyakana, in: Proc. of the $11^{\text {th }}$ Int. World Conference on Titanium (JIMIC5), M. Niinomi, S. Akiyama, M. Ikeda, M. Hagiwara, K. Maruyama (Eds.), Kyoto, Japan, 2007, pp. 713-716.

[10] Y. Kosaka, S. P. Fox, K. Faller and S. H. Reichman, Mater. Eng. Perform. 14 (6) (2005) 792-798.

[11] O. Schauerte, Adv. Eng. Mater. 5 (6) (2003) 411-418.

[12] L. Lutterotti, S. Gialanella. Acta Mater. 46 (1998) 101-110.

[13] H.M. Rietveld, Appl. Cryst. 2 (1969) 65.

[14] R. Flitney, Seals and Sealing Handbook, fifth ed., chapter 7, General information, Elsevier Science \& Technology in Oxford, UK, 2007. p. 478.

[15] M.G. Moore, W.P. Evans, SAE Trans., 66 (1958) 340-345.

[]16 Ch. Genzel, C. Stock and W. Reimers, Mater. Sci. Eng. A 372 (2004) 28-43.

[17] E. Kröner, Z. Phys. 151 (1958) 504-518.

[18] K. Zay, E. Maawad, H.-G. Brokmeier, L. Wagner and Ch. Genzel, Mater Sci. Eng. A 528 (2011) 2554-2558.

[19] C. Leyens, M. Peters (Eds.), Titanium and Titanium Alloys, Fundamentals and Applications, first ed., WILEY-Verlag GmbH \& Co. KGaA, Weinheim, Germany, 2003, p. 65.

[20] P. Prevéy, D. Hornbach, P. Mason, in: Proc. of the $17^{\text {th }}$ Heat Treating Society Conference and Exposition and the $1^{\text {st }}$ Int. Induction Heat Treating Symposium, D.L. Milam et al. (Eds.), ASM, Materials Park, OH, 1998, pp. 3-12 
[21] A. Medvedev, J. Bergström, S. Gunnarsson, P. Krakhmalev, Mater. Sci. Eng. A 5283 (2011) 1773.

[22] I. Nikitin, B. Scholtes , H.J. Maier, I. Altenberger, Scr. Mater. 50 (2004) 1345-1350.

[23] I. Nikitin, I. Altenberger, Mater. Sci. Eng. A 465 (2007) 176-182.

[24] L. Wagner, M. Mhaede, M. Wollmann, I. Altenberger, Y. Sano, Struct. Integr. 2-2 (2011) 185-199.

\section{Figures Captions}

Fig. 1. Experimental setup of $\mathrm{LPwC}$ process. ( $\mathrm{LPwC}=$ Laser shock peening without coating) Fig. 2. Scheme showing the typical procedure of laser irradiation on a flat specimen.

Fig. 3. Scheme showing a relation between energy $\left[\mathrm{E}_{(\mathrm{hk} .1)}\right]$ of a certain reflection (hk.l) of $\alpha-$ phase and maximum penetration depth $\left[\tau_{\max (\mathrm{hk} .1)} *\right]$ at $2 \theta=8^{\circ}$ using white X-ray beam.

${ }^{*} \tau_{\max (\mathrm{hk} . \mathrm{l})}$ corresponds to the minimum tilting angle $\psi=0^{\circ}$ and is calculated by $\tau_{(\mathrm{hkl})}=(\sin \theta \cdot \cos \psi) / 2 \mu=\sin 4^{\circ} / 2 \mu$, where $\mu$ is the linear absorption coefficient which depends upon $\mathrm{E}_{(\mathrm{hk} . \mathrm{l})}$.

Fig. 4. Optical microstructures of (a) Ti-2.5Cu, (b) Ti-54M and (c) LCB.

Fig. 5. Debye-Scherrer rings of (a) Ti-54M and (c) LCB obtained by monochromatic synchrotron radiation $(98.25 \mathrm{keV})$ as well as sum diffraction pattern of (b) Ti-54M and (d) LCB fitted by MAUD software.

Fig. 6. Surface roughness (Rz) of various Ti-alloys after LPwC

Fig. 7. Surface roughness after various surface treatments in $\mathrm{Ti}-2.5 \mathrm{Cu}(\mathrm{EP}=$ Electropolishing, $\mathrm{BB}=$ Ball-burnishing, $\mathrm{USP}=$ Ultrasonic shot peening, $\mathrm{SP}=$ Shot peening, LPwC $=$ Laser shock peening without coating).

Fig. 8. SEM surface images of (a) Ti-2.5Cu, (b) Ti-54M and (c) LCB after laser shock peening without coating ( $\mathrm{LPwC})$. 
Fig. 9. Microhardness-depth profiles in Ti-2.5Cu, Ti-54M and LCB surface layers after laser shock peening without coating (LPwC).

Fig. 10. Microhardness-depth profiles in Ti-2.5Cu after LPwC, SP, USP and BB.

$(\mathrm{LPwC}=$ Laser shock peening without coating, $\mathrm{SP}=$ Shot peening, USP $=$ Ultrasonic shot peening, $\mathrm{BB}=$ Ball-burnishing).

Fig. 11. Residual stress-depth profiles in $\mathrm{x}$ - and $\mathrm{y}$-directions in $\mathrm{Ti}-2.5 \mathrm{Cu}$ after laser shock peening without coating (LPwC) on both sides ( side-1 and side-2).

Fig. 12. Residual stress-depth profiles in y-direction in alpha phase of Ti-2.5Cu, Ti-54M and LCB after laser shock peening without coating ( $\mathrm{LPwC})$.

Fig. 13. Residual stress-depth profile in y-direction in beta-phase of LCB after laser shock peening without coating ( $\mathrm{LPwC})$.

Fig. 14. Residual stress-depth profiles in y-direction in alpha phase of Ti-2.5Cu after $\mathrm{LPwC}$, SP, USP and BB. $(\mathrm{LPwC}=$ Laser shock peening without coating, $\mathrm{SP}=$ Shot peening, $\mathrm{USP}=$ Ultrasonic shot peening, $\mathrm{BB}=$ Ball-burnishing).

Fig. 15. Plot $\lg \left[\ln \left(\sigma^{\mathrm{RS}}(\mathrm{t}=0) / \sigma^{\mathrm{RS}}(\mathrm{T}, \mathrm{t})\right)\right]$ versus $\lg (\mathrm{t})$ of $\mathrm{Ti}-2.5 \mathrm{Cu}$ after $(\mathrm{a})$ shot peening $(\mathrm{SP})$ and (b) laser shock peening without coating ( $\mathrm{LPwC})$.

Fig. 16. $\mathrm{S}-\mathrm{N}$ curves $(\mathrm{R}=-1)$, effect of laser shock peening without coating (LPwC) on (a) Ti2.5Cu, (b) Ti-54M and (c) LCB, compared with EP, SP, BB Ti-2.5Cu.

(EP = Electropolishing, $\mathrm{BB}=$ Ball-burnishing, USP = Ultrasonic shot peening, $\mathrm{SP}=$ Shot peening, $\mathrm{LPwC}=$ Laser shock peening without coating).

Fig. 17. HCF crack nucleation sites in (a) Ti-2.5Cu, (b) Ti-54M and (c) LCB after laser shock peening without coating $\mathrm{LPwC}$ compared to those in Ti-2.5Cu after shot peening (SP) and ball-burnishing (BB). 


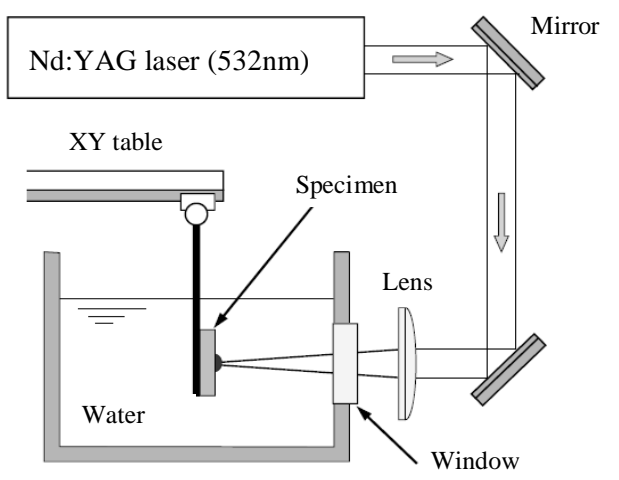

Fig. 1. Experimental setup of LPwC process.

$(\mathrm{LPwC}=$ Laser shock peening without coating $)$ 


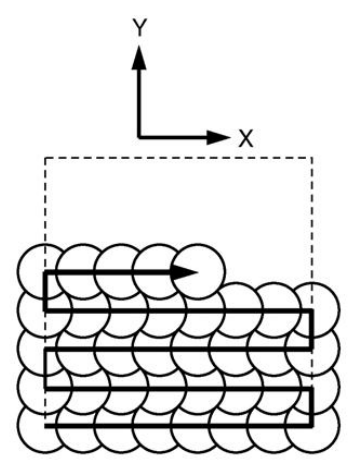

Fig. 2. Scheme showing the typical procedure of laser irradiation on a flat specimen. 


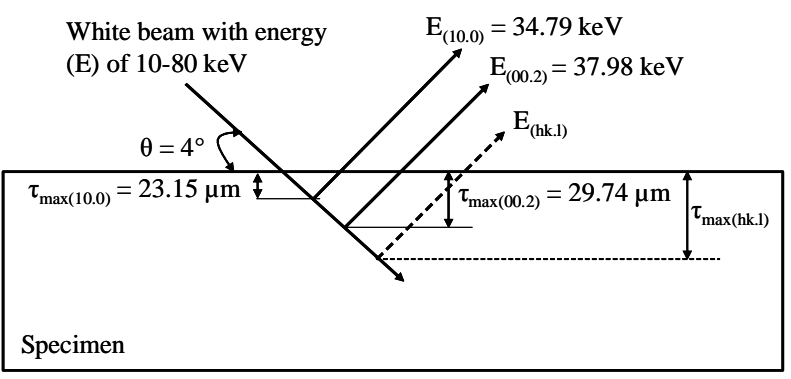

Fig. 3. Scheme showing a relation between energy $\left[\mathrm{E}_{(\mathrm{hk} . \mathrm{l})}\right]$ of a certain reflection (hk.l) of $\alpha-$ phase and maximum penetration depth $\left[\tau_{\max (\mathrm{hk} . \mathrm{l})}{ }^{*}\right]$ at $2 \theta=8^{\circ}$ using white X-ray beam.

* $\tau_{\max (\mathrm{hk.l} . \mathrm{l}}$ corresponds to the minimum tilting angle $\psi=0^{\circ}$ and is calculated by $\tau_{(\mathrm{hkl})}=(\sin \theta \cdot \cos \psi) / 2 \mu=\sin 4^{\circ} / 2 \mu$, where $\mu$ is the linear absorption coefficient which depends upon $\mathrm{E}_{(\mathrm{hk} . \mathrm{l})}$. 


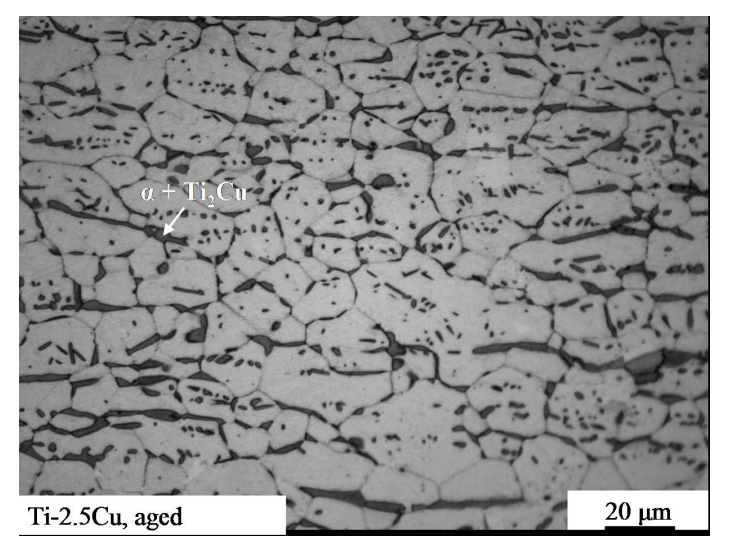

a) $\mathrm{Ti}-2.5 \mathrm{Cu}$

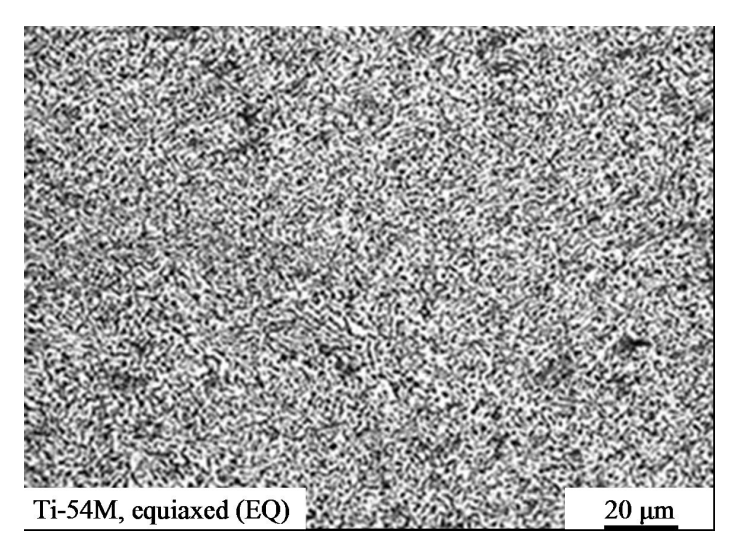

b) Ti-54M

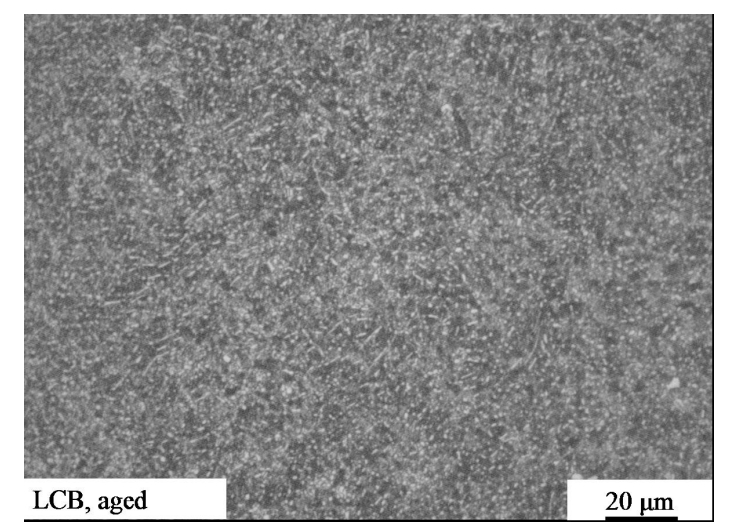

c) LCB

Fig. 4. Optical microstructures of (a) Ti-2.5Cu, (b) Ti-54M and (c) LCB. 


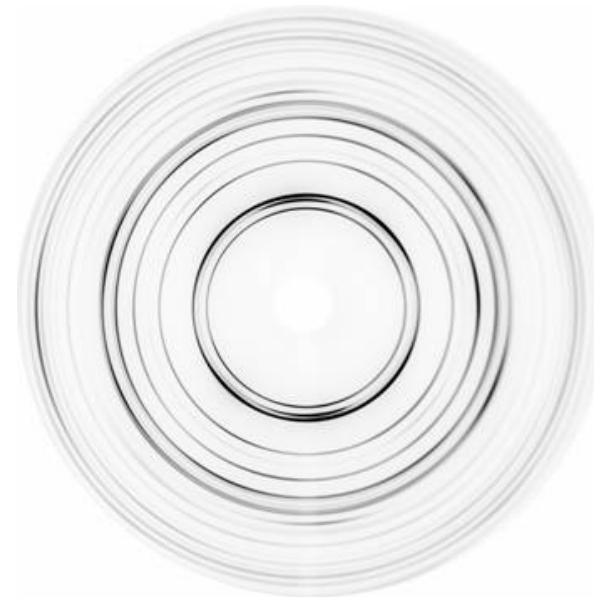

a) Debye-Scherrer rings of Ti-54M

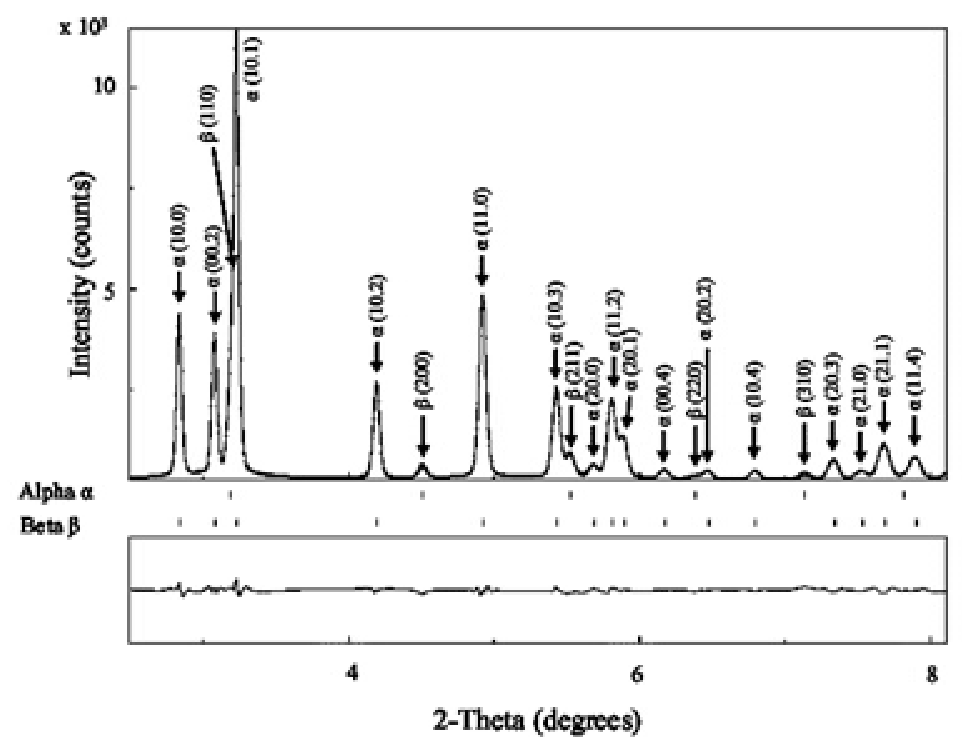

b) Fitted sum diffraction pattern of Ti-54M

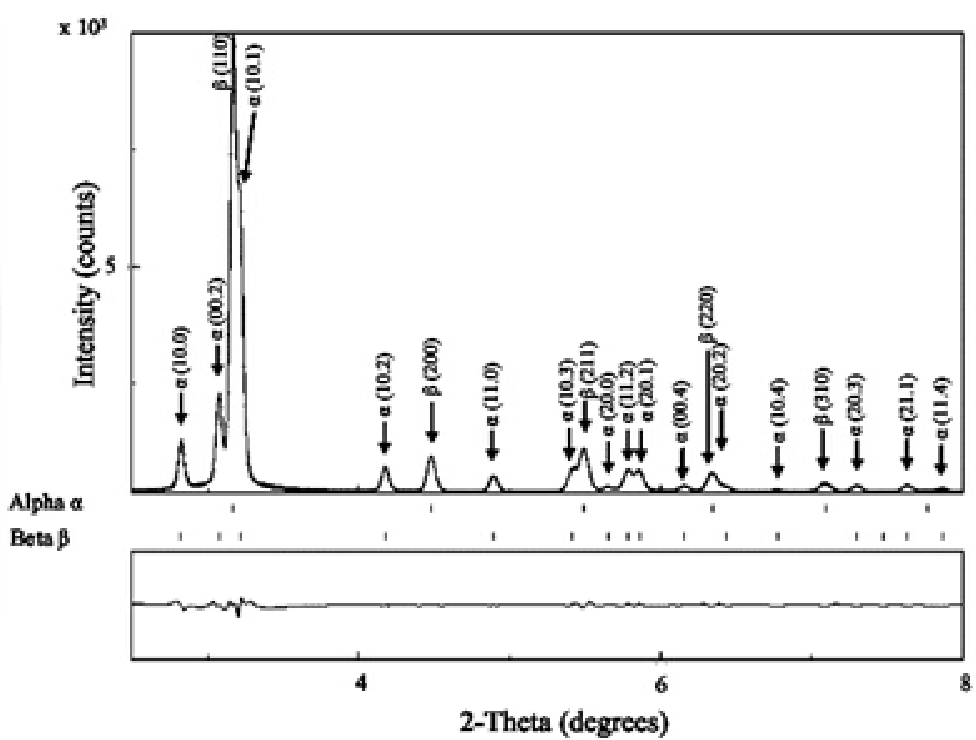

c) Debye-Scherrer rings of LCB d) Fitted sum diffraction pattern of LCB

Fig. 5. Debye-Scherrer rings of (a) Ti-54M and (c) LCB obtained by monochromatic synchrotron radiation $(98.25 \mathrm{keV})$ as well as sum diffraction pattern of (b) Ti-54M and (d) LCB fitted by MAUD software. 


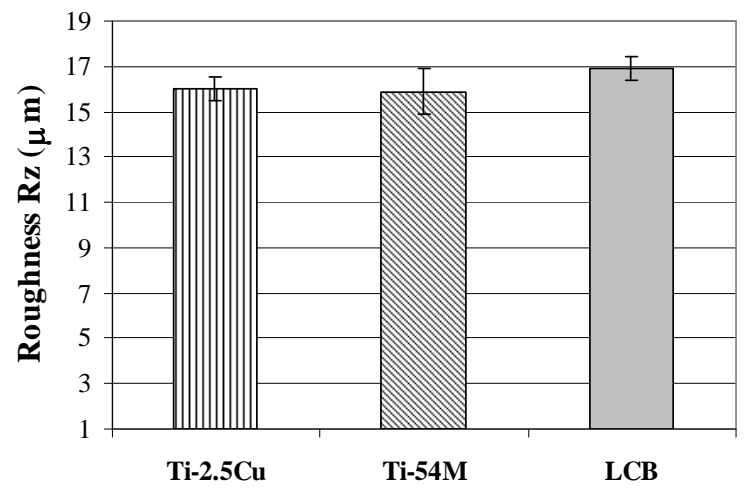

Fig. 6. Surface roughness (Rz) of various Ti-alloys after laser shock peening without coating (LPwC). 


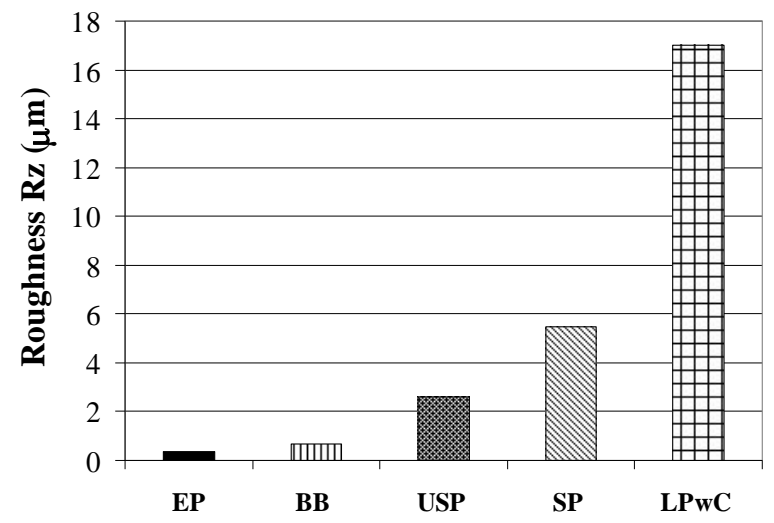

Fig. 7. Surface roughness after various surface treatments in $\mathrm{Ti}-2.5 \mathrm{Cu}$ $(\mathrm{EP}=$ Electropolishing, $\mathrm{BB}=$ Ball-burnishing, USP = Ultrasonic shot peening, $\mathrm{SP}=$ Shot peening, $\mathrm{LPwC}=$ Laser shock peening without coating). 


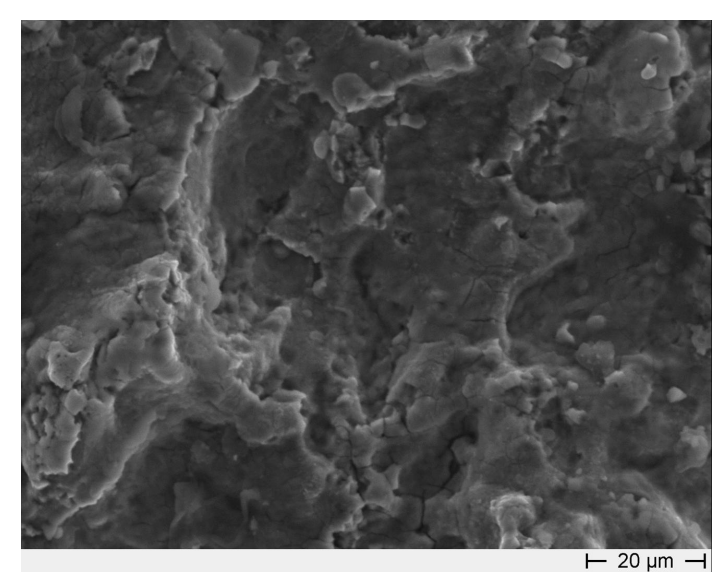

a) $\mathrm{Ti}-2.5 \mathrm{Cu}$

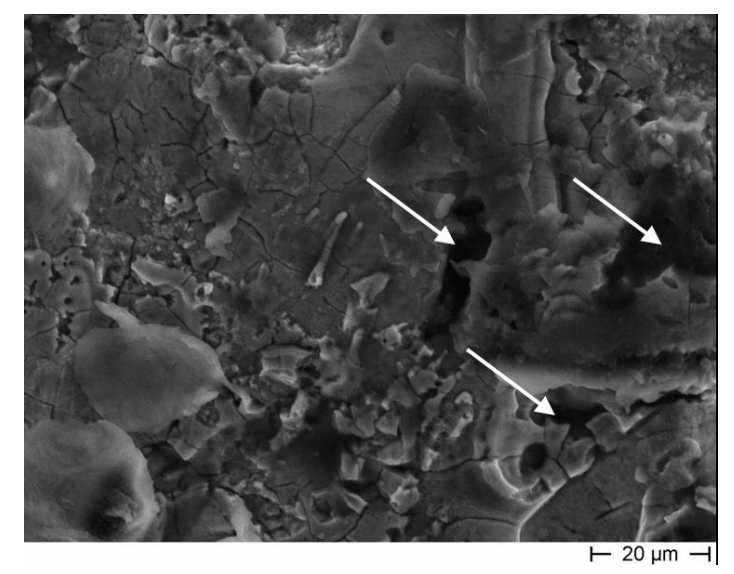

b) $\mathrm{Ti}-54 \mathrm{M}$

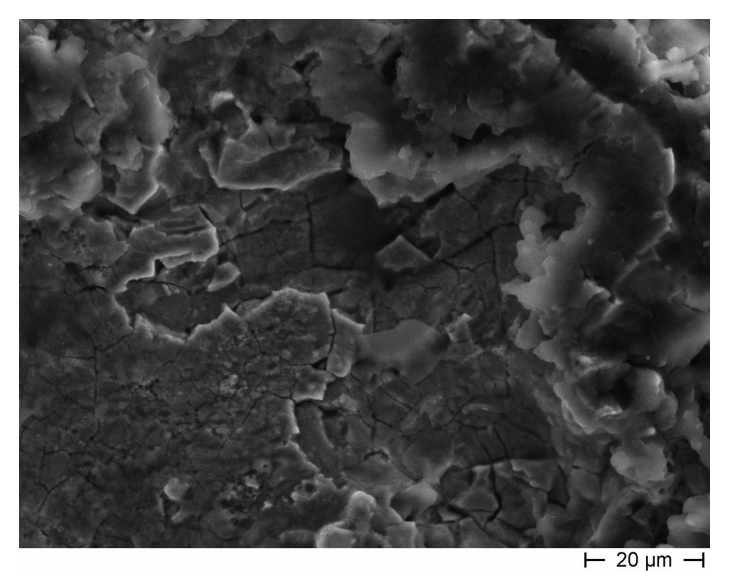

c) LCB

Fig. 8. SEM surface images of (a) Ti-2.5Cu, (b) Ti-54M and (c) LCB after laser shock peening without coating (LPwC). 


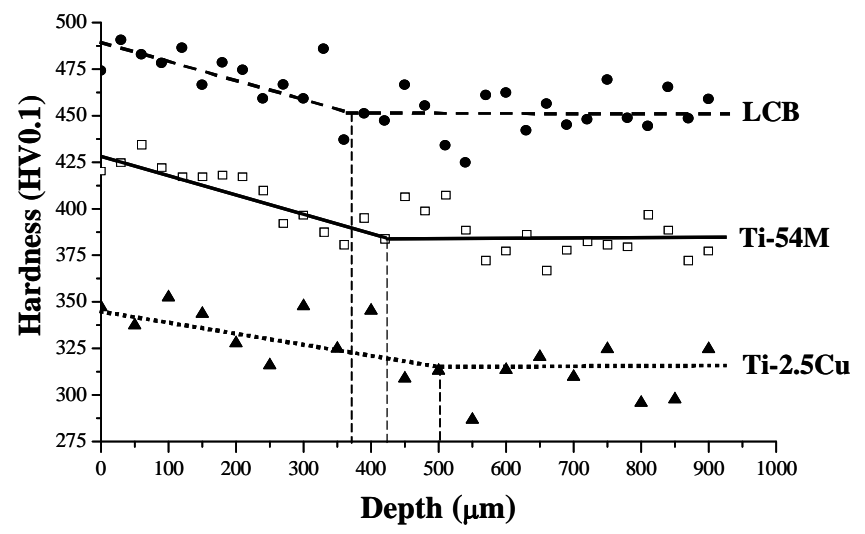

Fig. 9. Microhardness-depth profiles in $\mathrm{Ti}-2.5 \mathrm{Cu}$, Ti-54M and LCB surface layers after laser shock peening without coating (LPwC). 


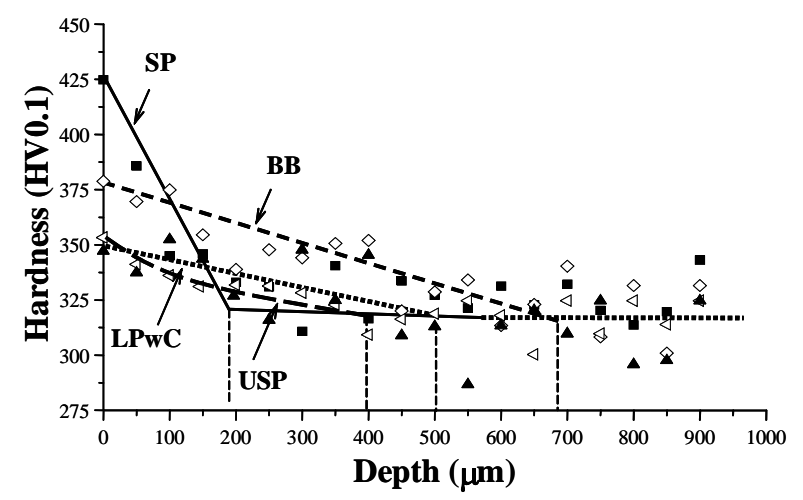

Fig. 10. Microhardness-depth profiles in Ti-2.5Cu after LPwC, SP, USP and BB.

(LPwC $=$ Laser shock peening without coating, $\mathrm{SP}=$ Shot peening, USP $=$ Ultrasonic shot peening, $\mathrm{BB}=$ Ball-burnishing). 


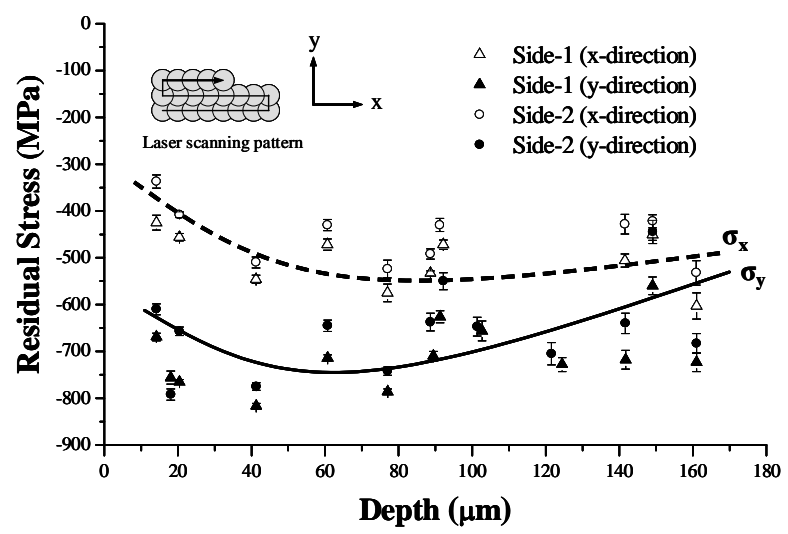

Fig. 11. Residual stress-depth profiles in $\mathrm{x}$ - and $\mathrm{y}$-directions in $\mathrm{Ti}-2.5 \mathrm{Cu}$ after laser shock peening without coating ( $\mathrm{LPwC}$ ) on both sides (side-1 and side-2). 


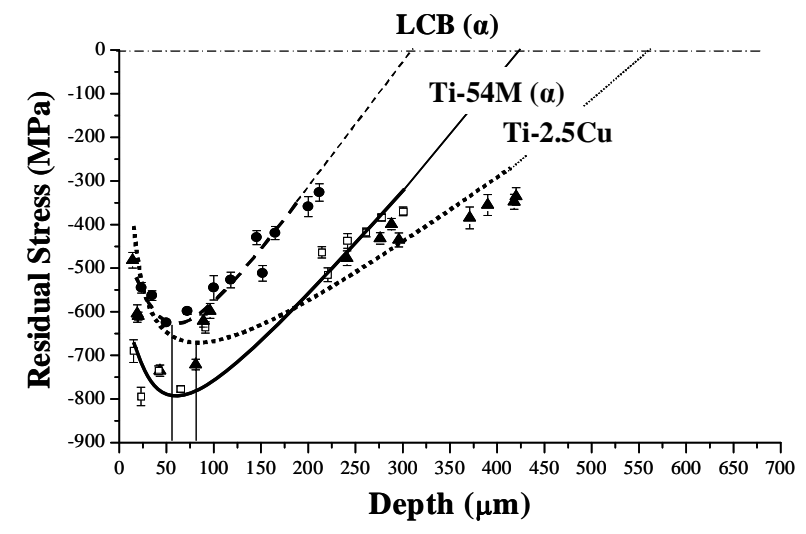

Fig. 12. Residual stress-depth profiles in y-direction in alpha phase of Ti-2.5Cu, Ti-54M and LCB after laser shock peening without coating (LPwC). 


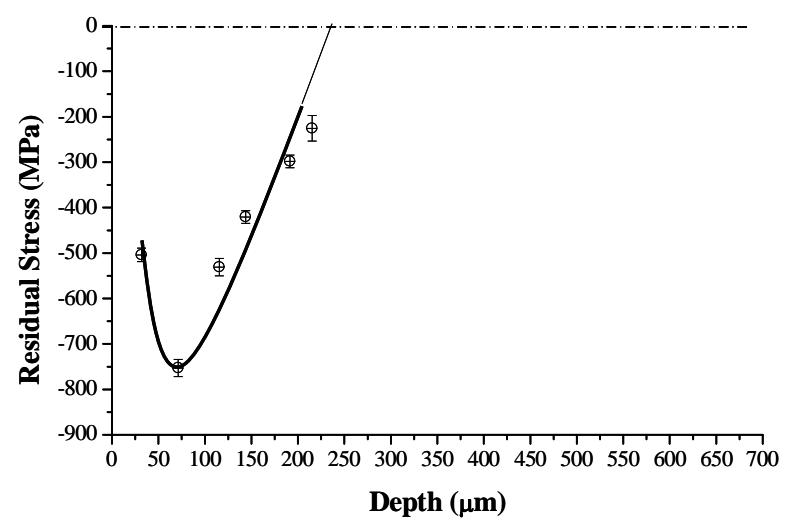

Fig. 13. Residual stress-depth profile in y-dirction in beta-phase of LCB after laser shock peening without coating $(\mathrm{LPwC})$. 


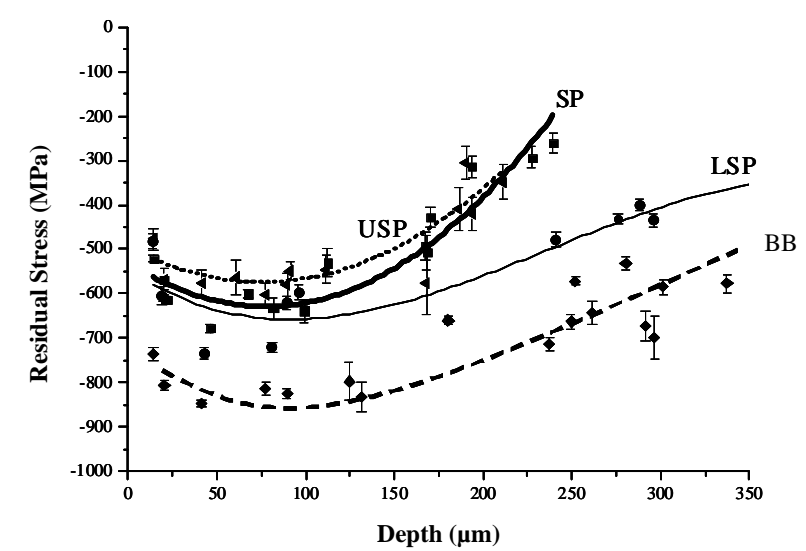

Fig. 14. Residual stress-depth profiles in y-direction in alpha phase of Ti-2.5Cu after LPwC, SP, USP and BB.

$(\mathrm{LPwC}=$ Laser shock peening without coating, $\mathrm{SP}=$ Shot peening, USP $=$ Ultrasonic shot peening, $\mathrm{BB}=$ Ball-burnishing). 


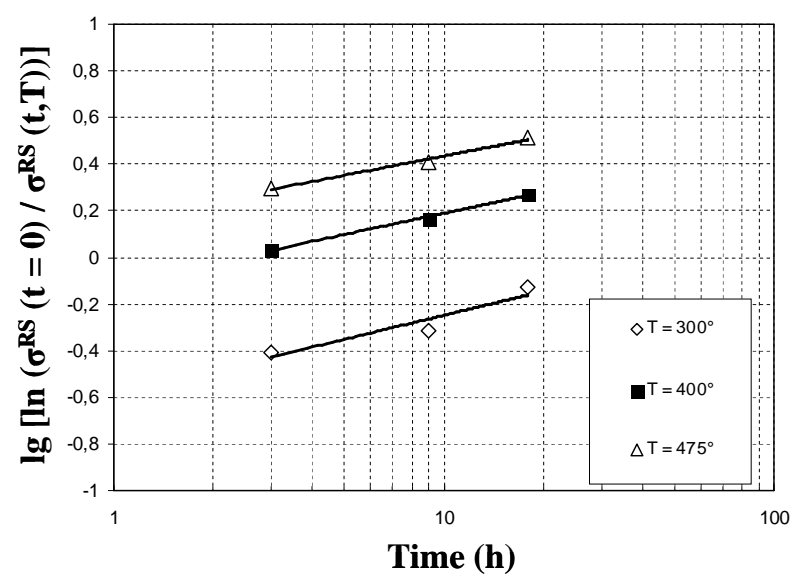

a) SP

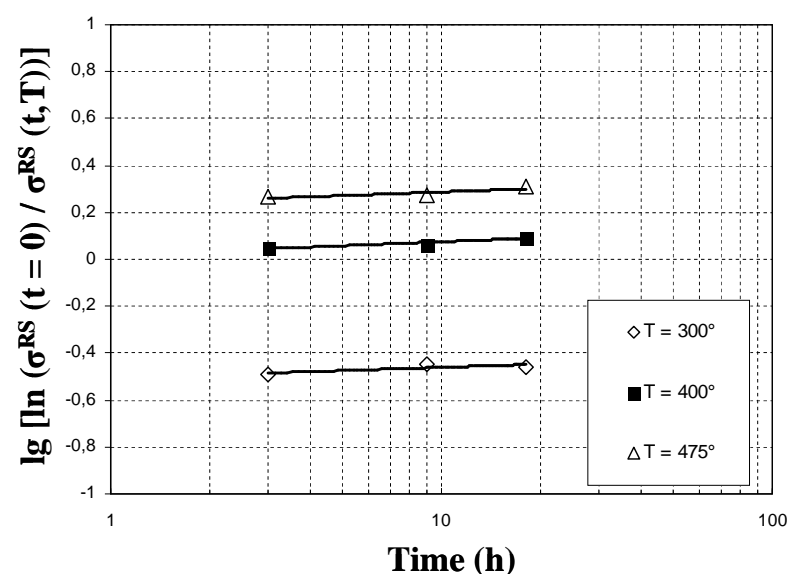

b) $\mathrm{LPwC}$

Fig. 15. Plot $\lg \left[\ln \left(\sigma^{\mathrm{RS}}(\mathrm{t}=0) / \sigma^{\mathrm{RS}}(\mathrm{T}, \mathrm{t})\right)\right]$ versus $\lg (\mathrm{t})$ of Ti-2.5Cu after (a) shot peening (SP) and (b)

laser shock peening without coating (LPwC) 


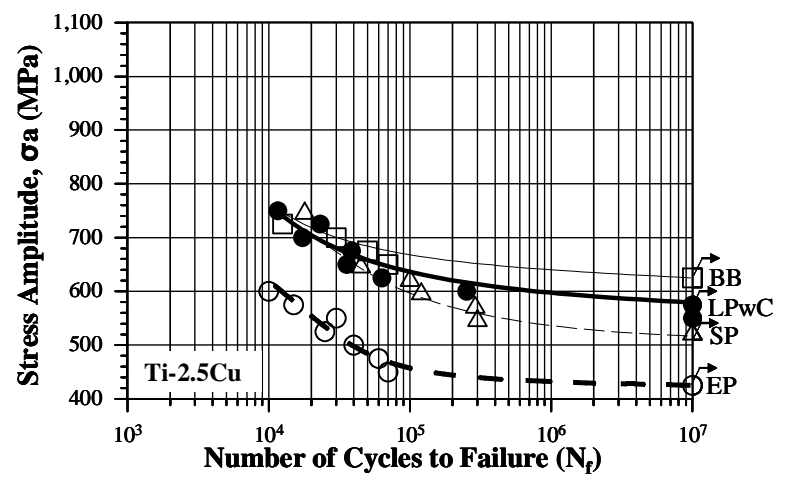

a) $\mathrm{Ti}-2.5 \mathrm{Cu}$

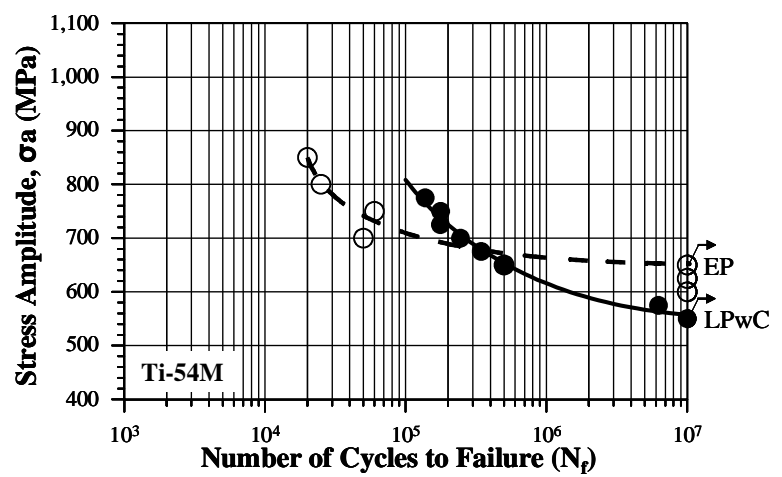

b) Ti-54M

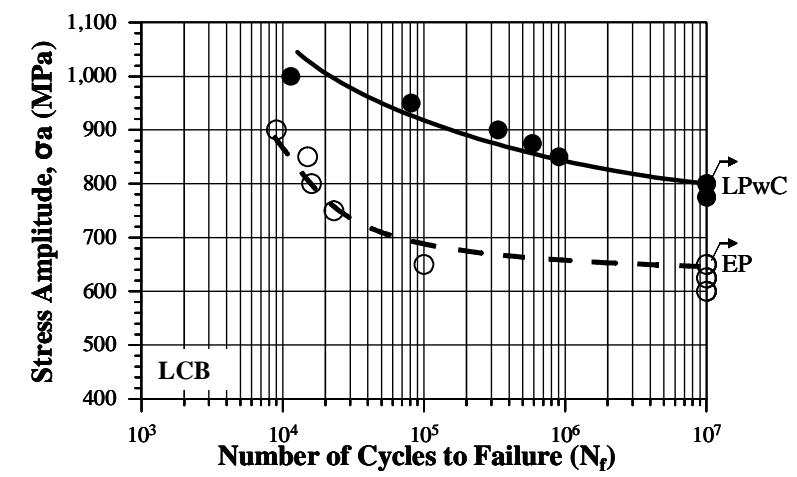

c) LCB

Fig. 16. S-N curves $(\mathrm{R}=-1)$, effect of laser shock peening without coating (LPwC) on (a) Ti2.5Cu, (b) Ti-54M and (c) LCB, compared with electropolished (EP), shot peening (SP) and ball-burnished (BB) Ti-2.5Cu. 

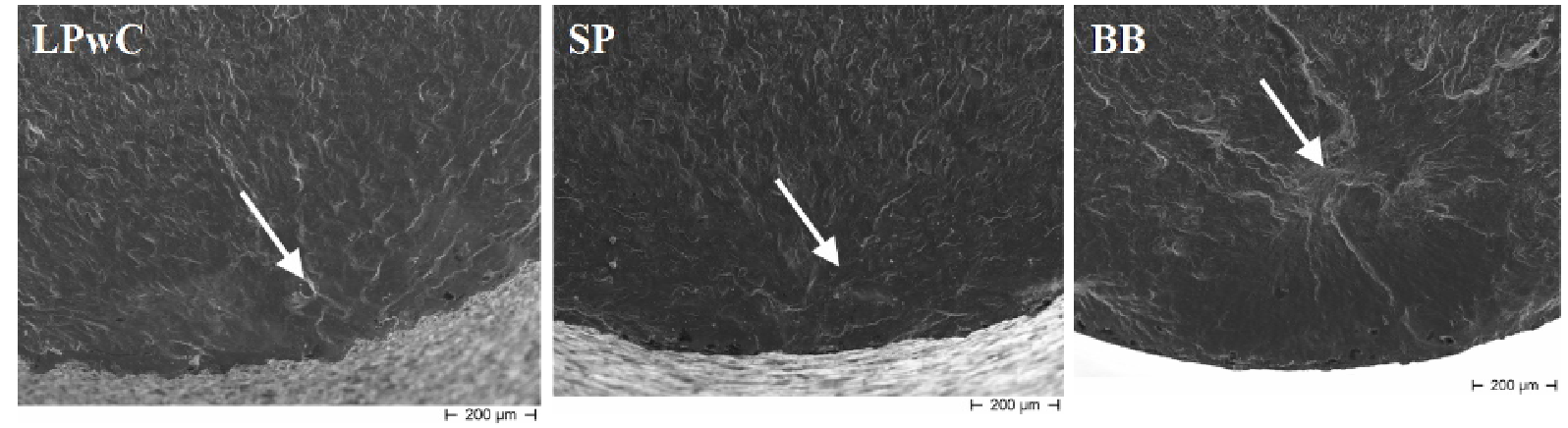

a) $\mathrm{Ti}-2.5 \mathrm{Cu}$
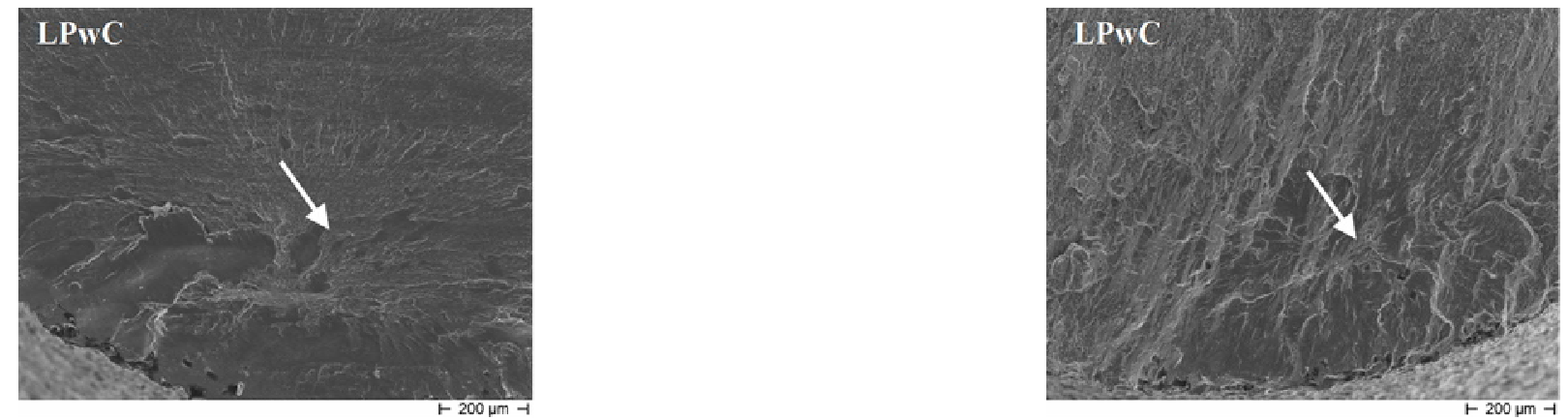

b) Ti-54M

c) LCB

Fig. 17. HCF crack nucleation sites in (a) Ti-2.5Cu, (b) Ti-54M and (c) LCB after laser shock peening without coating ( $\mathrm{LPwC}$ ) compared to those in $\mathrm{Ti}-2.5 \mathrm{Cu}$ after shot peeing (SP) and ball-burnishing (BB). 
Table 1. Tensile properties of Ti-2.5Cu, Ti-54M and LCB.

\begin{tabular}{ccccc}
\hline Alloy & $\begin{array}{c}\sigma_{0.2} \\
(\mathrm{MPa})\end{array}$ & $\begin{array}{c}\mathrm{UTS} \\
(\mathrm{MPa})\end{array}$ & $\begin{array}{c}\mathrm{El} \\
(\%)\end{array}$ & $\begin{array}{c}\varepsilon_{\mathrm{F}}= \\
\ln \left(\mathrm{A}_{\mathrm{o}} / \mathrm{A}_{\mathrm{F}}\right)\end{array}$ \\
Ti-2.5Cu & 685 & 770 & 16.4 & 0.57 \\
Ti-54M & 1145 & 1145 & 12.6 & 0.62 \\
LCB & 1260 & 1345 & 14.7 & 0.28 \\
\hline
\end{tabular}


Table 2. Parameters of Laser shock peening without coating

\begin{tabular}{lll}
\hline Parameter & & Possible variations \\
$\mathrm{E}_{\mathrm{p}}(\mathrm{mJ})$ & 50 & \pm 2 \\
$\mathrm{D}(\mathrm{mm})$ & 0.4 & \pm 0.03 \\
$\mathrm{~N}_{\mathrm{p}}\left(\mathrm{mm}^{-2}\right)$ & 127 & \pm 0.1 \\
$\mathrm{C}_{\mathrm{v}}$ & 16 & \pm 2 \\
$\mathrm{G}\left(\mathrm{GW} . \mathrm{cm}^{-2}\right)$ & 5 & \pm 0.6 \\
\hline
\end{tabular}


Table 3. Fitting parameters of Ti-54M and LCB using pole figure data.

\begin{tabular}{|c|c|c|c|}
\hline Phase & Model Parameter & Ti-54M & LCB \\
\hline \multirow{3}{*}{$\alpha$-Phase } & Volume Fraction \% & 84.2 & 15.7 \\
\hline & Weight Fraction \% & 83.4 & 15.0 \\
\hline & Lattice Constant $\AA$ & $\begin{array}{l}a=2.93467 \\
c=4.68544\end{array}$ & $\begin{array}{l}a=2.94980 \\
c=4.68915\end{array}$ \\
\hline \multirow{3}{*}{$\beta$-Phase } & Volume Fraction \% & 15.8 & 84.3 \\
\hline & Weight Fraction $\%$ & 16.6 & 85.0 \\
\hline & Lattice Constant $\AA$ & $a=3.20586$ & $\mathrm{a}=3.22406$ \\
\hline
\end{tabular}


Table 4. Residual stress component $\left(\sigma_{\mathrm{y}}\right)$ at the surface of Ti-2.5Cu, Ti-54M and LCB.

\begin{tabular}{lll}
\hline & $\begin{array}{l}\text { Surface residual } \\
\text { stress }(\mathrm{MPa})\end{array}$ & Error $(\mathrm{MPa})$ \\
\cline { 2 - 3 } Ti-2.5Cu & -390 & \pm 16 \\
Ti-54M & -650 & \pm 33 \\
LCB & -450 & \pm 26 \\
\hline
\end{tabular}


Table 5.Calculated parameters of Zener-Wert-Avrami function for SP and LPwC Ti-2.5Cu.

\begin{tabular}{|c|c|c|c|c|c|}
\hline & $\mathrm{m}$ & $\begin{array}{c}\Delta \mathrm{H} \\
(\mathrm{eV})\end{array}$ & $\begin{array}{c}\mathrm{C} \\
(1 / \mathrm{hr})\end{array}$ & $\begin{array}{l}\text { Microhardness at the depth } \\
\text { of maximum residual stress } \\
\text { (HV0.1) }\end{array}$ & Relaxation rate \\
\hline $\mathrm{SP}^{*}$ & 0.13 & 2.80 & $1.30 \times 10^{20}$ & 385 & faster \\
\hline LPwC* & 0.02 & 5.60 & $3.20 \times 10^{26}$ & 335 & slower \\
\hline
\end{tabular}

